\title{
Quality of life and functional outcome after infravesical desobstruction and HIFU treatment for localized prostate cancer
}

\author{
G. Hatiboglu*, I. V. Popeneciu, M. Deppert, J. Nyarangi-Dix, B. Hadaschik, M. Hohenfellner, D. Teber ${ }^{\dagger}$ \\ and S. Pahernik ${ }^{\dagger}$
}

\begin{abstract}
Background: To evaluate quality of life, functional and oncological outcome after infravesical desobstruction and HIFU treatment for localized prostate cancer.

Methods: One hundred thirty-one patients, treated with TURP and HIFU in a single institution were followed up for oncological and functional outcome. Oncological outcome was quantified by biochemical recurrence free survival using the Stuttgart and Phoenix criteria. Quality of life was assessed by usage of standardized QLQ-C30 and QLQPR25 questionnaires. In addition, functional questionnaires such as IPSS and IIEF-5 were used. Complications were assessed by the Clavien-Dindo classification.
\end{abstract}

Results: One hundred thirty-one patients with a mean age of 72.8 years (SD: 6.0) underwent HIFU for prostate cancer (29.0\% low risk, $58.8 \%$ intermediate risk, $12.2 \%$ high risk). PSA nadir was $0.6 \mathrm{ng} / \mathrm{ml}$ (SD: 1.2) after a mean of 4.6 months (SD: 5.7). Biochemical recurrence free survival defined by Stuttgart criteria was 73.7\%, 84.4\% and 62.5\% for low-, intermediate- and high-risk patients after 22.2 months. Complications were grouped according to Clavien-Dindo and occurred in $10.7 \%$ (grade II) and $11.5 \%$ (grade IIIa) of cases. $35.1 \%$ of patients needed further treatment for bladder neck stricture. Regarding incontinence, $14.3 \%, 2.9 \%$ and $0 \%$ of patients had de novo urinary incontinence grade $\mathrm{I}^{\circ}, \mathrm{I}^{\circ}$ and $\mathrm{II}^{\circ}$ and 3.8\% urge incontinence due to HIFU treatment. Patients were asked for the ability to have intercourse: 15.8\%, 58. $6 \%$ and $66.7 \%$ of patients after non-, onesided and bothsided nervesparing procedure were able to obtain sufficient erection for intercourse, respectively. Regarding quality of life, mean global health score according to QLQ-C30 was 69. $4 \%$.

Conclusion: HIFU treatment for localized prostate cancer shows acceptable oncological safety. Quality of life after HIFU is better than in the general population and ranges within those of standard treatment options compared to literature. HIFU seems a safe valuable treatment alternative for patients not suitable for standard treatment.

Keywords: HIFU, Quality of life, Outcome

\section{Background}

High intensified focused ultrasound (HIFU) is a minimal invasive, thermoablative treatment option for patients with localized prostate cancer. Its aim is equivalent oncological safety with reduced toxicity, compared to standard treatment options [1]. HIFU can be performed in general or spinal anesthesia via transrectal approach.

\footnotetext{
* Correspondence: gencay.hatiboglu@med.uni-heidelberg.de

${ }^{\dagger}$ Equal contributors

Department of Urology, University of Heidelberg, Im Neuenheimer Feld 110, 69120 Heidelberg, Germany
}

Focused, high energetic ultrasound waves cause thermal alteration and cavitation, causing coagulative necrosis and thereby destroying malignant tissue $[2,3]$.

Since the initial presentation in 1995 [4], several studies have evaluated oncological and functional outcome after HIFU. Recent publications report of $76 \%, 63 \%$ and $57 \%$ biochemical free survival after 8 years for low-, intermediate- and high-risk patients [5]. The 10-year prostate cancer specific survival rate and metastasis-free survival rate were $97 \%$ and $94 \%$, respectively [5]. Regarding morbidity of HIFU treatment, severe incontinence 
rates of $3.1 \%$ and erectile function preservation of up to $42.3 \%$ are described [5]. Patients rejecting standard treatment and preferring HIFU do this with the expectation for less complications and less invasiveness compared to standard treatment. Especially incontinence, erectile dysfunction after radical prostatectomy as well as gastrointestinal and genitourinary side effects after radiotherapy are feared by many patients and can impair their quality of life [6]. Recent studies have evaluated quality of life for prostate cancer patients after local therapy, showing good results with moderate alteration in erectile and lower urinary tract function with minimal decrease in quality of life $[7,8]$. The authors utilized standardized questionnaires for this evaluation like the European Organisation for Research and Treatment of cancer (EORTC) quality of life questionnaire QLQ-C30 and the prostate specific module QLQ-PR25. The QLQ-C30 questionnaire evaluates overall health related quality of life as well as several functional domains and general cancer related symptoms. The QLQ-PR25 assesses urinary symptoms, sexual activity and function, as well as bowel symptoms. Both questionnaires have been evaluated and validated extensively $[9,10]$. Regarding quality of life for prostate cancer patients, both questionnaires are routinely used.

To our knowledge, data about quality of life after HIFU therapy using standardized questionnaires are rare and have not been evaluated in a standardized fashion so far. The aim of the study was to investigate prospectively quality of life after HIFU ablation of the prostate for the local treatment of prostate cancer.

\section{Methods}

One hundred thirty-one patients undergoing infravesical desobstruction and HIFU treatment for localized prostate cancer between 02/2008 and 12/2012 were followed up in a prospectively conducted database. The study protocol was approved by the ethics committee of the University of Heidelberg (S-182/2012). All patients gave written informed consent.

All patients were treated with the Ablatherm HIFU device (Ablatherm integrated imaging device; EDAP-TMS, Vaulx-en-Velin, France). Before HIFU treatment an infravesical desobstruction was routinely done one day prior to HIFU treatment, normally by transurethral resection of the prostate (TURP) or by greenlight laservaporisation of the prostate [11]. The mode of infravesical desobstruction was at patients' preference (TUR-P was recommended, some patients explicitly wished to undergo greenlight laservaporisation). HIFU treatment was performed as inpatient procedure in combined spinal and epidural anesthesia. Nervesparing procedure was only done in patients explicitly demanding for this. All these patients were intensively informed about higher risk for recurrent prostate cancer but wished to undergo nervesparing anyway and with awareness of all risks (this was also documented in informed consent). In these cases, mainly one sided nervesparing was done - if prostate biopsy showed cancer infiltration on only one side the nervesparing was done on the contralateral side. However, some patients explicitly wished both sided nervesparing, taking into account the risk for tumor recurrence. For all patients, the following parameters were assessed and entered in a prospective conducted database: patient age, body mass index, prostate volume, PSA value at diagnosis, Gleason Score, clinical stage, risk classification (according to D'Amico et al. [12, 13]), PSA nadir and time to PSA nadir, biochemical recurrence according to Stuttgart criteria [14] and Phoenix criteria [15]. In addition, treatment related data were evaluated and included: type of preoperative infravesical desobstruction, duration and number of applied lesions during HIFU treatment, nervesparing (non-,unilateral-,bilateral nervesparing), hospital stay, indwelling time for transurethral and suprapubic catheter, uroflowmetry and residual volume (pre-HIFU and 2 weeks post-HIFU). In addition, complication were evaluated according to Clavien-Dindo [16]. Patients were asked to fill out the international prostate symptom score (IPSS) and international index for erectile function (IIEF-5) questionnaire before and 3 months after HIFU treatment. Continence was evaluated and graduated during followup, the usage and number of used pads was evaluated. Patients were also asked for sexual activity after HIFU treatment including the usage of adjuvant medication for erection.

\section{Assessment of quality of life}

All patients were asked to complete the European Organisation for Research and Treatment of cancer (EORTC) quality of life questionnaire QLQ-C30 (Version 3.0) and the prostate specific module QLQ-PR25 retrospectively in $12 / 2012$. Both questionnaires are internationally validated and used in cancer patients. They were used in German translation. The QLQ-C30 questionnaire consists of 30 questions, the QLQ-PR25 of 25 questions. The QLQ-C30 measures global health related quality of life, five functional domains (physical, role, emotional, cognitive and role function) and nine symptom scales (fatigue, nausea and vomiting, pain, dyspnoe, insomnia, appetite loss, constipation, diarrhea, financial difficulties). The QLQ-PR25 questionnaire, consisting of 25 questions, assesses urinary symptoms, bowel symptoms, treatment-related symptoms and sexual symptoms and functioning. In both instruments, all answers ranged from 1 (not at all) to 4 (very much), despite 2 questions in the QLQ-C30 considering global health related quality of life ranging from 1 (very poor) to 7 (excellent). 
Both questionnaires have been interpreted according to the EORTC guidelines. The scores have been converted to linear scales ranging from 0 to 100 . Higher values in functional scales and health related quality of life represent better results. Lower values in symptom scales represent less symptoms.

\section{Statistical analysis}

Above mentioned variables were evaluated by descriptive statistics. Median, mean, standard deviation and range were calculated for every variable using Microsoft Excel and IBM SPSS statistics version 20.

\section{Results}

One hundred thirty-one patients with a mean age of $72.8 \pm 6.0$ years have been included to this analysis. PSA values at prostate cancer diagnosis were $9.6 \pm 14.9 \mathrm{ng} /$ ml. Gleason score was 6 in 57 patients (43.5\%), 7 in 66 patients $(50.4 \%)$ and $\geq 8$ in 8 patients (6.1\%). $29.0 \%$ of patients had a low risk, $58.8 \%$ an intermediate risk and $12.2 \%$ a high risk prostate cancer (Table 1 ). When presenting for HIFU treatment, 28 patients (21.4\%) have been on neoadjuvant hormonal therapy, that has been stopped directly after HIFU treatment. Bothsided nervesparing was performed in $21.1 \%, 9.6 \%$ and $6.7 \%$, onesided nervesparing in $28.9 \%, 26.0 \%$ and $6.7 \%$ of low-, intermediate- and high-risk patients, respectively. After HIFU the mean PSA nadir was $0.6 \pm 1.2 \mathrm{ng} / \mathrm{ml}$ (median: $0.1 \mathrm{ng} / \mathrm{ml}$; range $0.01-6.50 \mathrm{ng} / \mathrm{ml}$ ) and reached after 4.7 months (SD: 5.7) (Table 2). Mean follow up was 22.2 months (SD: 16.1$) .28$ patients $(21.4 \%)$ developed a biochemical recurrence, defined as PSA Nadir $+1.2 \mathrm{ng} /$ $\mathrm{ml}$ (according to Stuttgart criteria [14]) after a mean

Table 1 Demographics

\begin{tabular}{lll}
\hline & $\mathrm{n}(\%)$ & mean (SD) \\
\hline Age (years) & 131 & $72.8(6.0)$ \\
Clinical stage & & \\
$\quad$ CT1 & $83(63.8 \%)$ & \\
$\quad \geq \mathrm{cT} 2$ & $47(36.2 \%)$ & \\
Gleason Score & & \\
$\quad \leq 6$ & $57(43.5 \%)$ & \\
7 & $66(50.4 \%)$ & \\
$\quad \geq 8$ & $8(6.1 \%)$ & \\
inital PSA (ng/ml) & 130 & \\
Risk stratification (D'Amico) & & \\
Low - risk & $38(29.0 \%)$ & \\
Intermediate - risk & $77(58.8 \%)$ & \\
$\quad$ High - risk & $16(12.2 \%)$ & $26.7(25.6)$ \\
Prostate volume (ml) & 130 & \\
Prostate volume after resection & 123 & \\
\hline
\end{tabular}

Table 2 Perioperative parameter

\begin{tabular}{lll}
\hline & $\mathrm{n}(\%)$ & mean (SD) \\
\hline Treated HIFU volume (ml) & 126 & $27.7(9.9)$ \\
Duration of HIFU treatment (minutes) & 127 & $104.3(28.8)$ \\
Applied lesions & 127 & $433.8(136.2)$ \\
Nervesparing & & \\
$\quad$ No nervesparing & $79(60.3 \%)$ & \\
$\quad$ One-sided nervesparing & $31(23.7 \%)$ & \\
$\quad$ Both-sided nervesparing & $16(12.2 \%)$ & \\
$\quad$ Data missing & $5(3.8 \%)$ & \\
Transurethral catheter indwelling time & 125 & $4.0(2.5)$ \\
Suprapubic catheter indwelling time & 78 & $14.5(15.0)$ \\
\hline
\end{tabular}

time of $15.5 \pm 11.6$ months. Among them, 10 patients (26.3\%), 12 patients (15.6\%) and 6 patients (37.5\%) of low-, intermediate-and high-risk profile, respectively. Therefore, biochemical recurrence free survival was $73.7 \%, 84.4 \%$ and $62.5 \%$ for low-, intermediate- and high-risk patients at latest follow-up. In addition, 3 patients had histological confirmed recurrence that was confirmed in prostate biopsy in patients undergoing biopsy after 6 months at own wish or after bladder neck resection due to infravesical obstruction.

Of these 31 patients with recurrent prostate cancer, 18 patients (58.1\%) underwent active therapy. Twelve of these patients were lost to follow-up. Five patients underwent salvage radiotherapy, two 2 patients salvageHIFU therapy, one patient prostatectomy and one patient brachytherapy and pelvic lymphadenectomy. The other 9 patients $(29.0 \%)$ did not wish salvage therapy and received antiandrogen treatment. During follow-up, 7 patients (5.3\%) deceased - 1 patient because of systemic progression of the prostate cancer, the other 6 patients due to cardiovascular events (Table 3).

When defining biochemical recurrence according to Phoenix criteria, 20 patients (15.5\%) showed biochemical recurrence with a mean time to recurrence of $17.4 \pm$ 12.5 months. Biochemical recurrence free survival was therefore $81.6 \%, 89.6 \%$ and $68.8 \%$ for low-, intermediateand high-risk patients at latest follow-up, respectively.

Regarding treatment data, 109 patients (83.2\%) underwent TUR-P, 18 patients greenlight-laser vaporization $(13.7 \%)$ and 1 patient $(0.8 \%)$ combination of both in advance to HIFU treatment. Resection was done the day prior to HIFU. Mean prostate size was thereby reduced from $43.7 \mathrm{ml}( \pm 25.6)$ to $26.0 \mathrm{ml}( \pm 12.5)$. Three patients (2.3\%) had no prior infravesical desobstruction. During HIFU treatment, a one-sided nervesparing was done in 31 patients (23.7\%), a both sided nervesparing in 16 patients $(12.2 \%)$. Perioperative side effects up to 30 days after HIFU treatment were assessed and grouped according to Clavien-Dindo classification and occurred in 
Table 3 Oncological outcome

\begin{tabular}{|c|c|c|}
\hline & n (\%) & Mean (SD) \\
\hline PSA - nadir (ng/ml) & 101 & $\begin{array}{l}0.6(1.2) \\
\text { median: } 0.1 \\
\text { (range: } 0.01-6.50)\end{array}$ \\
\hline Time to nadir (months) & 99 & $4.7(5.7)$ \\
\hline Recurrencies & $31(23.7 \%)$ & \\
\hline $\begin{array}{l}\text { Biochemical recurrence (BCR) } \\
\text { Suttgart criteria }\end{array}$ & $28(21.4 \%)$ & \\
\hline low - risk - PCa & $10(7.6 \%)$ & \\
\hline intermediate - risk - PCa & $12(9.2 \%)$ & \\
\hline high - risk - PCa & $6(4.6 \%)$ & \\
\hline $\begin{array}{l}\text { Time to BCR (in months) } \\
\text { (Stuttgart criteria) }\end{array}$ & 28 & $15.5(11.6)$ \\
\hline $\begin{array}{l}\text { Time to BCR (in months) } \\
\text { (Phoenix criteria) }\end{array}$ & & $17.4(12.5)$ \\
\hline low - risk - PCa & 10 & $14.1(8.2)$ \\
\hline intermediate - risk - PCa & 12 & $19.8(13.8)$ \\
\hline high - risk - Pca & 6 & $11.3(5.4)$ \\
\hline Recurrence without $B C R$ & $3(2.3 \%)$ & \\
\hline
\end{tabular}

25 patients (19.1\%), 4 patients had 2 complications. Main complications were infravesical obstruction and urinary tract infections. With respect to infravesical obstruction, grade II and grade IIIa complications occurred in $14(10.7 \%)$ and $15(11.5 \%)$ cases, respectively. Regarding late complications beyond 30 days, 47 patients (35.9\%) needed further treatment. 46 patients (35.1\%) needed catheterization or suprapubic catheter insertion and transurethral resection because of bladder neck obstruction. One patients needed DJ insertion because progression of prostate cancer.

IPSS score before and after HIFU treatment was 10.9 \pm 7.1 and $9.2 \pm 6.2$, respectively. Uroflowmetrie before and after HIFU treatment showed max. flow of $14.0 \mathrm{ml} /$ $\mathrm{s}(\mathrm{SD} 8.2$ ) and $14.1 \mathrm{ml} / \mathrm{s}$ (SD 8.7) with post voiding residual volume of $45.5 \mathrm{ml}$ (SD 69.4) and $54.0 \mathrm{ml}$ (SD 93.6), respectively. Regarding incontinence, $14.3 \%$, $2.9 \%$ and $0 \%$ of patients had de novo urinary incontinence grade $\mathrm{I}^{\circ}, \mathrm{II}^{\circ}$ and $\mathrm{III}^{\circ}$ and $3.8 \%$ urge incontinence due to HIFU treatment. Before HIFU treatment $97.1 \%$ of patients did not need a pad. After HIFU treatment, 9.5\%, $6.7 \%$ and $1.9 \%$ of patients needed 1 pad, 2 pads or $>2$ pads, respectively, meaning $81.9 \%$ did not need a pad at all at latest follow-up.

IIEF-5 scores showed $17.2 \pm 7.3$ and $9.7 \pm 8.0$ before and after HIFU treatment in all patients, respectively. When grouped according to nervesparing procedure, mean IIEF-5 score before and after HIFU was $15.1 \pm 8.1$ vs. $7.5 \pm 7.4$ for the non-nervesparing group, $19.7 \pm 4.8$ vs. $12.5 \pm 8.3$ for the one-sided nervesparing group and $20.7 \pm 5.3$ and $12.1 \pm 7.5$ for the both sided nervesparing group, respectively. Regarding the ability to have sexual intercourse, $15.8 \%, 58.6 \%$ and $66.7 \%$ of patients after non-, onesided and bothsided nervesparing procedure were able to obtain sufficient erection for intercourse, respectively. $33.3 \%$ of these patients used PDE5 inhibitors, 3 patients mechanical devices to obtain erection. Functional outcomes after HIFU therapy are displayed in Table 4.

Quality of life was evaluated using the QLQ-C30 questionnaire and showed a global health status of $69.4 \%$ (SD: 20.6). Functional scales revealed physical functioning of $86.2 \%$ (SD 17.7) after HIFU treatment. Regarding symptom scales, fatigue and insomnia were the most frequent symptoms with $25.9 \%$ (SD: 24.8 ) and $31.4 \%$ (SD: 31.4 ) of cases in a cohort of men aged $72.8 \pm 6.0$ years. For further evaluation of prostate specific symptoms the QLQ-PR25 questionnaire was used and showed sexual activity and functioning of $56.9 \%$ (SD: 28.1) and $49.6 \%$ (SD: 20.5), respectively. Evaluation of symptom scales showed urinary symptoms in $28.3 \%$ (SD: 18.4) and

Table 4 Functional outcome after HIFU treatment (mean(SD))

\begin{tabular}{|c|c|c|}
\hline & Pre - HIFU & Post - HIFU \\
\hline \multicolumn{3}{|l|}{ Continence and micturation symptoms } \\
\hline IPSS - Score & $10.9(7.1)$ & $9.2(6.2)$ \\
\hline Micturation volume (ml) & $207.7(116.5)$ & $189.2(92.4)$ \\
\hline Post voiding Residual volume(ml) & $45.5(69.4)$ & $54.0(93.6)$ \\
\hline Qmax (ml/sec) & $14.0(8.2)$ & $14.1(8.7)$ \\
\hline \multicolumn{3}{|l|}{ Continence } \\
\hline Continent & $93(88.6 \%)$ & $71(67.6 \%)$ \\
\hline Incontince grade $1^{\circ}$ & $5(4.8 \%)$ & $20(19.0 \%)$ \\
\hline Incontince grade $\|^{\circ}$ & $0(0.0 \%)$ & $3(2.9 \%)$ \\
\hline Incontince grade $\mid \|^{\circ}$ & $1(1.0 \%)$ & $1(1.0 \%)$ \\
\hline Urge incontinence & $6(5.7 \%)$ & $10(9.5 \%)$ \\
\hline \multicolumn{3}{|l|}{ Pad usage } \\
\hline No pads & $102(97.1 \%)$ & $86(81.9 \%)$ \\
\hline $1 \mathrm{pad}$ & $1(1.0 \%)$ & $10(9.5 \%)$ \\
\hline 2 pads & $1(1.0 \%)$ & $7(6.7 \%)$ \\
\hline$>2$ pads & $1(1.0 \%)$ & $2(1.9 \%)$ \\
\hline \multicolumn{3}{|l|}{ Sexual function } \\
\hline \multicolumn{3}{|l|}{ Sexual intercourse after HIFU } \\
\hline Yes & & $36(35.6 \%)$ \\
\hline No & & $65(64.4 \%)$ \\
\hline Due to HIFU treatment & & $46(45.5 \%)$ \\
\hline Other reason & & $55(54.5 \%)$ \\
\hline \multicolumn{3}{|l|}{ IIEF - 5} \\
\hline IIEF - 5 - score & $17.2(7.3)$ & $9.7(8.0)$ \\
\hline IIEF - 5 - non - nervesparing & $15.1(8.1)$ & $7.5(7.4)$ \\
\hline IIEF - 5 - onesided - nervesparing & $19.7(4.8)$ & $12.5(8.3)$ \\
\hline IIEF - 5 - bothsided - nervesparing & $20.7(5.3)$ & $12.1(7.5)$ \\
\hline
\end{tabular}


urinary bother in 38.6\% (SD: 35.6) of patients after HIFU. Bowel symptoms did appear in 6.7\% (SD: 11.2) of patients. The overall quality of life did not change before and after HIFU (evaluated by the IPSS questionnaire). All results are displayed in Table 5.

\section{Discussion}

The present study was performed to evaluate quality of life after HIFU treatment for prostate cancer. To our knowledge, this is the first study investigating this topic. Quality of life was assessed by standardized questionnaires. In addition, functional outcome and oncological results were evaluated with respect to limited followup.

Regarding oncological results, recent reports from Crouzet et al. showed 7 years biochemical free survival

Table 5 Quality of life - post-HIFU outcome of QLQ-C30, QLQPR25 and IPSS-QoL questionnaires $(n=105)$. Data are shown as mean with standard deviation

QLQ - C30

Global health status/QoL (QL2)

$69.4(20.6)$

Functional scales

Physical functioning (PF2)

$86.2(17.7)$

Role functioning (RF2)

$79.0(29.9)$

Emotional functioning (EF)

$74.8(23.5)$

Cognitive functioning (CF)

Social functioning (SF)

$83.3(20.5)$

$74.8(25.0)$

Symptom scales/items

Fatigue (FA)

$25.9(24.8)$

Nausea and vomiting (NV)

Pain (PA)

Dyspnoea (DY)

Insomnia (SL)

Appetite loss (AP)

Constipation (CO)

Diarrhoea (DI)

Financial difficulties (FI)

QLQ - PR25

Functional scales

Sexual activity(PRSAC) $(n=104)$

Sexual functioning (PRSFU) $(n=71)$

Symptom scales/items

Urinary symptoms (PRURI)

Urinary bother (PRAID)

Bowel symptoms (PRBOW)

ADT - treatments symptoms (PRHTR)

Quality - of - life; IPSS

Prä - HIFU

$2.1(1.4)$

Post - HIFU

$2.0(1.3)$
(Phoenix Criteria) in 75\%, 63\% and 62\% for low-, intermediate- and high-risk prostate cancer patients [5]. Using the recently supposed stricter Stuttgart criteria (meaning PSA nadir $+1.2 \mathrm{ng} / \mathrm{ml}$ [14]), Pfeiffer et al. described 5 years biochemical free survival as 85\%, 65\% and $55 \%$ for low-, intermediate- and high-risk prostate cancer [17]. The present series mainly consisted of intermediate risk patients (58.8\%) because high risk patients were consulted for standard treatment and low risk patients for active surveillance. In this cohort, biochemical recurrence free survival was $76.3 \%, 84.4 \%$ and $64.7 \%$ (using Stuttgart criteria) and 81.6\%, 89.6\% and 68.8\% (using Phoenix criteria) for low-, intermediate- and high-risk patients with a mean follow up of 22.2 months. However, 3 patients of our cohort also had histological proven recurrence without biochemical recurrence. Previous studies by Ganzer et al. showed, that negative biopsy rates correlate with postoperative PSA nadir. Ganzer et al. described negative biopsy rates of $91.6 \%$ for patients with PSA nadir $\leq 0.2 \mathrm{ng} / \mathrm{ml}$. Thus, $8.4 \%$ of patients had remaining prostate cancer tissue in control biopsies after 3-6 months [14] with a PSA value $<0.2 \mathrm{ng} / \mathrm{ml}$.

In our cohort, side effects were limited in severity. Main complications were urinary tract infections and infravesical obstruction. While infections were mainly managed successfully by antibiotic treatment, $25 \%$ of patients needed further surgical treatment in form of transurethral resection of bladder neck strictures. These complications and rates were also described in other publications as the most frequent re-interventions [18-20]. More severe complications like fistulas did not occur in our cohort. Regarding postoperative micturition and continence, IPSS and uroflowmetry data did not change after HIFU treatment. Previous studies could show, that combining TURP and HIFU is mandatory to reduce postoperative voiding dysfunction [21]. However, even previous TURP cannot reduce infravesical obstruction completely. During followup, 35.1\% of patients needed further treatment for infravesical obstruction after HIFU treatment. Previous studies confirm, that bladder neck obstruction or urethral strictures are the most common side effects of HIFU treatment $[5,18]$. Crouzet et al. described up to $16 \%$ bladder neck obstruction in their group, when TUR-P and HIFU were combined in one session. To reduce these side effects, an interval of up to 6 weeks between TUR-P and HIFU has been proposed [11] with reduction of infravesical obstruction to $11 \%$, as described by Crouzet et al. [5] Compared to our cohort, median pre-HIFU prostate volume was smaller in the cohort described by Crouzet et al. (22-24.5 ml) compared to our cohort $(38.5 \mathrm{ml})$, which could explain the higher bladder neck obstruction rates in the present study due to a selection bias.

Evaluation of erectile function in our group revealed, that postoperative erectile function depends 
on nervesparing procedure. Most studies do not report of nervesparing as this means sparing a few millimeters of prostatic tissue and therefore increasing the risk for biochemical recurrence [22]. As expected, the PSA nadir ranges were higher (up to $6.5 \mathrm{ng} / \mathrm{ml}$ ), most likely because of nervesparing procedure, that has been done in $35.9 \%$ of patients. Warmuth et al. [18] reviewed 20 studies with a total of 3018 patients undergoing whole gland ablation and reported of erectile dysfunction rates ranging from 20 $39 \%$. Crouzet et al. [5] recently reported their results of 1002 patients and described preservation of erectile function in $42.3 \%$ patients ( $<70$ years: $55.6 \%$; $>70$ years: $25.6 \%)$. None of these trials took nervesparing procedure into account. In our cohort, erectile function could be preserved in only $15 \%$ in patients undergoing whole gland ablation. These patients tended to be of advanced age (mean age in non-nervesparing group was 74.4 years), that is known to be associated with impaired baseline potency status [23] and therefore these patients normally do not wish nervesparing procedure. In contrast, both sided nervesparing HIFU could preserve erectile function in up to $66 \%$ of our patients (median age in this group was 69.7 years).

Patients undergoing HIFU ablation instead of standard treatment commonly expect less side effects and better preservation of quality of life. As quality of life represents a multidimensional construct that includes physical, social, psychological and functional domains, its assessment needs complex and standardized questionnaires. Shoji et al. examined the changes in quality of life for patients at a mean age 68 years undergoing HIFU by using the japanese versions of the FACT-G and FACT-P questionnaires (functional assessment of cancer therapy - general and prostate cancer module) [24]. The authors reported, that general quality of life improves after HIFU therapy while the values for FACT-P questionnaire did not change. However, patients undergoing HIFU may be biased as they actively rejected standard therapy for a new, minimal invasive therapy option. We evaluated quality of life after HIFU therapy using the standardized QLQ-C30 and QLQ-PR25 questionnaire. Mean global health score after HIFU treatment was $69.4 \%$ for all patients, $66.4 \%$ for patients $\leq 70$ years and $70.9 \%$ for patients $>70$ years. Schwarz et al. evaluated QLQ-C30 data for the general german population [25] and described global health scores of $65.6 \%$ and $61.5 \%$ for patients $\leq 70$ and $>70$ years, respectively. When compared to the general german population, patients after HIFU treatment show better quality of life with respect to global health scores. Drummond et al. evaluated quality of life after standard therapy in more than 6000 patients within the PiCTure study (prostate cancer treatment, your experience) [8]. They described global health scores ranging from $73.4 \%$ for radical prostatectomy and $69.4 \%$ for external beam radiation therapy. With respect to the younger patient collective in the PiCTure study, global health score after HIFU treatment in our collective ranged within the scores after standard treatment options described by Drummond et al. Comparing the results of QLQ-PR25 items revealed more urinary symptoms $(28.3 \%$ for HIFU vs. $19.8 \%$ for standard treatment [8]) and more urinary bother (38.6\% for HIFU vs. $15.6 \%$ for standard treatment [8]) and less sexual activity (56.9\% for HIFU vs. $67.8 \%$ for standard treatment [8]).

Limitations of the study include short followup. Results predicting oncological safety need longer followup periods, that should be considered in further studies. Another limitation is the missing, preoperative assessment for quality of life to compare changes for this parameter.

\section{Conclusion}

In conclusion, HIFU treatment for localized prostate cancer shows acceptable oncological safety in limited follow up. However, local recurrence is not always indicated by biochemical recurrence. Compared to literature, the quality of life after HIFU showed better results compared to general population of equivalent age. Patients' satisfaction ranges within those of standard treatment options. Further studies are needed to compare changes in quality of life before and after HIFU therapy. In addition, nearly $25 \%$ of patients needed further treatment for bladder neck obstruction. HIFU seems a safe valuable treatment alternative for patients not suitable for standard treatment.

\section{Abbreviations \\ EORTC: European Organisation for Research and Treatment of cancer: HIFU: High intensified focused ultrasound; IIEF-5: International index for erectile function; IPSS: International prostate symptom score; QLQ: Quality of life questionnaire; TURP: Transurethral resection of the prostate}

\section{Availability of data and materials}

The datasets generated and/or analysed during the current study are not publicly available due to ethical restrictions but are available from the corresponding author on reasonable request.

\section{Authors' contribution}

GH, IVP and MD carried out data acquisition and data analysis. GH participated in design of the study and drafted the manuscript. JND, DT and $\mathrm{BH}$ helped in designing the study and revised the manuscript critically. SP, DT and $\mathrm{MH}$ made substantial contribution to conception and design, analysis of data, critically revising the manuscript and final approval. DT and SP contributed equally. All authors read and approved the final manuscript.

\section{Competing interests}

The authors declare that they have no competing interests.

\section{Ethics approval and consent to participate}

The study protocol was approved by the ethics committee of the University of Heidelberg (S-182/2012). All patients gave written informed consent. Nervesparing was only done in patients, explicitly demanding for this with full awareness of higher risk of tumor recurrence. This was also documented in the informed consent.

Received: 4 August 2015 Accepted: 5 January 2017

Published online: 11 January 2017 


\section{References}

1. Heidenreich A, Bellmunt J, Bolla M, Joniau S, Mason M, Matveev V, et al EAU guidelines on prostate cancer. Part 1: screening, diagnosis, and treatment of clinically localised disease. Eur Urol. 2011;59(1):61-71. doi:10. 1016/j.eururo.2010.10.039

2. Chaussy CG, Thuroff S. Transrectal high-intensity focused ultrasound for local treatment of prostate cancer: current role. Arch Esp Urol. 2011;64(6):493-506.

3. Madersbacher S, Marberger M. High-energy shockwaves and extracorporeal high-intensity focused ultrasound. J Endourol. 2003;17(8):667-72. doi:10. 1089/089277903322518680

4. Madersbacher S, Pedevilla M, Vingers L, Susani M, Marberger M. Effect of high-intensity focused ultrasound on human prostate cancer in vivo. Cancer Res. 1995:55(15):3346-51.

5. Crouzet S, Chapelon JY, Rouviere O, Mege-Lechevallier F, Colombel M, Tonoli-Catez $\mathrm{H}$, et al. Whole-gland ablation of localized prostate cancer with high-intensity focused ultrasound: oncologic outcomes and morbidity in 1002 patients. Eur Urol. 2014;65(5):907-14. doi:10.1016/j.eururo.2013.04.039.

6. Osoba D. Health-related quality of life and cancer clinical trials. Ther Adv Med Oncol. 2011;3(2):57-71. doi:10.1177/1758834010395342.

7. Miller DC, Sanda MG, Dunn RL, Montie JE, Pimentel H, Sandler HM, et al. Longterm outcomes among localized prostate cancer survivors: health-related quality-of-life changes after radical prostatectomy, external radiation, and brachytherapy. J Clin Oncol. 2005;23(12):2772-80. doi:10.1200/JCO.2005.07.116.

8. Drummond FJ, Kinnear H, O'Leary E, Donnelly, Gavin A, Sharp L. Long-term health-related quality of life of prostate cancer survivors varies by primary treatment. Results from the PiCTure (Prostate Cancer Treatment, your experience) study. J Cancer Surviv. 2015. doi:10.1007/s11764-014-0419-6.

9. Groenvold M, Klee MC, Sprangers MA, Aaronson NK. Validation of the EORTC QLQ-C30 quality of life questionnaire through combined qualitative and quantitative assessment of patient-observer agreement. J Clin Epidemiol. 1997;50(4):441-50

10. Niezgoda HE, Pater JL. A validation study of the domains of the core EORTC quality of life questionnaire. Qual Life Res. 1993;2(5):319-25.

11. Chaussy C, Thuroff S. The status of high-intensity focused ultrasound in the treatment of localized prostate cancer and the impact of a combined resection. Curr Urol Rep. 2003:4(3):248-52.

12. D'Amico AV, Moul J, Carroll PR, Sun L, Lubeck D, Chen MH. Cancer-specific mortality after surgery or radiation for patients with clinically localized prostate cancer managed during the prostate-specific antigen era. J Clin Oncol. 2003:21(11):2163-72. doi:10.1200/JCO.2003.01.075.

13. D'Amico AV, Whittington R, Malkowicz SB, Schultz D, Blank K, Broderick GA, et al. Biochemical outcome after radical prostatectomy, external beam radiation therapy, or interstitial radiation therapy for clinically localized prostate cancer. JAMA. 1998;280(11):969-74

14. Ganzer R, Robertson CN, Ward JF, Brown SC, Conti GN, Murat FJ, et al. Correlation of prostate-specific antigen nadir and biochemical failure after high-intensity focused ultrasound of localized prostate cancer based on the Stuttgart failure criteria - analysis from the @-Registry. BJU Int. 2011;108(8 Pt 2):E196-201. doi:10.1111/j.1464-410X.2011.10091.X.

15. Roach 3rd M, Hanks G, Thames Jr H, Schellhammer P, Shipley WU, Sokol GH, et al. Defining biochemical failure following radiotherapy with or without hormonal therapy in men with clinically localized prostate cancer: recommendations of the RTOG-ASTRO Phoenix Consensus Conference. Int J Radiat Oncol Biol Phys. 2006;65(4):965-74. doi:10.1016/j.jirobp.2006.04.029.

16. Dindo D, Demartines N, Clavien PA. Classification of surgical complications: a new proposal with evaluation in a cohort of 6336 patients and results of a survey. Ann Surg. 2004;240(2):205-13.

17. Pfeiffer D, Berger J, Gross AJ. Single application of high-intensity focused ultrasound as a first-line therapy for clinically localized prostate cancer: 5-year outcomes. BJU Int. 2012;110(11):1702-7. doi:10.1111/j.1464-410X.2012.11375.x.

18. Warmuth M, Johansson T, Mad P. Systematic review of the efficacy and safety of high-intensity focussed ultrasound for the primary and salvage treatment of prostate cancer. Eur Urol. 2010;58(6):803-15. doi:10.1016/j. eururo.2010.09.009.

19. Blana A, Rogenhofer S, Ganzer R, Lunz JC, Schostak M, Wieland WF, et al. Eight years' experience with high-intensity focused ultrasonography for treatment of localized prostate cancer. Urology. 2008;72(6):1329-33. doi:10. 1016/j.urology.2008.06.062. discussion 33-4.

20. Ganzer R, Fritsche HM, Brandtner A, Brundl J, Koch D, Wieland WF, et al. Fourteen-year oncological and functional outcomes of high-intensity focused ultrasound in localized prostate cancer. BJU Int. 2013;112(3):322-9. doi:10.1111/j.1464-410X.2012.11715.x.

21. Chaussy CG, Thuroff SF. Robotic high-intensity focused ultrasound for prostate cancer: what have we learned in 15 years of clinical use? Curr Urol Rep. 2011;12(3):180-7. doi:10.1007/s11934-011-0184-2.

22. Chaussy C, Thuroff S. Results and side effects of high-intensity focused ultrasound in localized prostate cancer. J Endourol. 2001;15(4):437-40. doi: 10.1089/089277901300189501. discussion 47-8.

23. Burke RM, Evans JD. Avanafil for treatment of erectile dysfunction: review of its potential. Vasc Health Risk Manag. 2012;8:517-23. doi:10.2147/NHRM.S26712.

24. Shoji S, Nakano M, Nagata Y, Usui Y, Terachi T, Uchida T. Quality of life following high-intensity focused ultrasound for the treatment of localized prostate cancer: a prospective study. Int J Urol. 2010;17(8):715-9. doi:10. 1111/j.1442-2042.2010.02568.x.

25. Schwarz R, Hinz A. Reference data for the quality of life questionnaire EORTC QLQ-C30 in the general German population. Eur J Cancer. 2001; $37(11): 1345-51$

\section{Submit your next manuscript to BioMed Central and we will help you at every step:}

- We accept pre-submission inquiries

- Our selector tool helps you to find the most relevant journal

- We provide round the clock customer support

- Convenient online submission

- Thorough peer review

- Inclusion in PubMed and all major indexing services

- Maximum visibility for your research

Submit your manuscript at www.biomedcentral.com/submit

) Biomed Central 